\title{
Particularities of Larynx Cancer in Women in Senegal
}

\author{
Ahmed Houra ${ }^{1 *}$, Ndour Ngor ${ }^{1}$, Ndiaye Ciré ${ }^{1}$, Pilor Ndongo ${ }^{1}$, Tall Hady ${ }^{2}$, Mbaye Aminata ${ }^{1}$, Sall Ahmadou Cheikhou ${ }^{1}$, \\ Ndiaye Moustapha ${ }^{1}$, Diom Evelyne Siga ${ }^{3}$, Ndiaye Malick ${ }^{4}$ and Ndiaye Issa Cheikh ${ }^{1}$ \\ ${ }^{1}$ ENT Department and Cervical-Facial Surgery (CSF), National University Hospital of Fann, Senegal
}

${ }^{2}$ ENT Department and Cervical-Facial Surgery (CSF), Saint Louis Regional Hospital, Senegal

${ }^{3}$ ENT Department and Cervical-Facial Surgery (CSF) service, Ziguinchor Peace Hospital, Senegal

${ }^{4}$ ENT Department and Cervical-Facial Surgery (CSF), Diamniadio Children's Hospital, Senegal

*Corresponding author: Ahmed Houra, ENT Department and Cervical-Facial Surgery (CSF), National University Hospital of Fann, Senegal

\begin{abstract}
Summary
Introduction: Laryngeal cancer is the second most common cancer of the head and neck. It is a predominantly male cancer, its occurrence in women is rare. The purpose of this work is to present the results of the analysis of 20 cases of women with laryngeal cancer.

Material and Method: Between 2009 and 2018, 20 patients were treated for laryngeal cancer in our department. We studied the socio-demographic characteristics of this population and determined the risk factors that may have influenced the occurrence of laryngeal cancer in these women.

Results: This study involves 20 women with an average age of 51.2 years. In $70 \%$ of the cases they are housewives, in $15 \%$ of the shopkeepers, and in $5 \%$ of the matrons. A notion of exposure to smoking was found in $15 \%$ of cases. Exposure to wood smoke was found in $80 \%$ with an average exposure time of 30 years. The major symptom was dysphonia, present in $100 \%$ of patients at the time of diagnosis. It was associated in $80 \%$ with laryngeal dyspnea, in $30 \%$ with dysphagia, in $40 \%$ with reflex otalgia. Laryngeal endoscopy revealed a budding and hemorrhagic tumor in $47.51 \%$ of cases. A total of $55 \%$ of the patients had stage 4 cancer; distant metastasis was found in 3 patients. Treatment consisted of total laryngectomy in $60 \%$ of cases, and organ preservation in 1 case. The evolution was marked in $10 \%$ by recurrence and $40 \%$ by death.
\end{abstract}

Conclusion: Although in our study exposure to wood smoke appears to be a significant risk factor for the occurrence of this cancer, further study would confirm the exact role of this factor and improve the prognosis.

Keywords: Cancer; woman; larynx; wood smoke

\section{Introduction}

Cancer of the larynx, the second most common cancer of the head and neck, has long been considered a cancer of the human body in relation to the classic risk factors of alcohol and tobacco [15]. In women, this cancer is rare and ranks 26th, but its incidence rate seems to be increasing over the years [6]. To this end, we focused on the Senegalese female population suffering from this cancer. The aim of this study is to show the existence of this cancer in Senegalese women who are practically not exposed to the classic risk factors.

\section{Patients and Methods}

This retrospective, descriptive and monocentric study concerns 20 cases of laryngeal cancer in women with histological evidence, collected over a period of 10 years (from January 1, 2009 to December 31, 2018), in the university ENT department Lamine Sine Diop of the National UHC of Fann (Dakar, Senegal). We have excluded from this work all the laryngeal cancer files of the male subject and incomplete files without histology. The following 
parameters were studied: age, risk factors, clinical and paraclinical data, treatments carried out, histological results, and evolution after treatment. The data obtained were entered into Excel and analysed by the statistical package for social science (SPSS version 20).

\section{Results}

\section{Epidemiological aspects}

During this period, we counted 20 women suffering from laryngeal cancer, i.e. $3.89 \%$ of all cases of laryngeal cancer diagnosed during these 10 years. The average age was 51.7 years with extremes of 32 and 70 years. Concerning the profession or occupations of our patients, they were housewives in $70 \%$ of cases, shopkeepers in $15 \%$ of cases, cooks in $10 \%$ and matrons in $5 \%$ of cases. A notion of tobacco intoxication was found in 15\% of the patients. Exposure to wood smoke was reported in 16 patients, i.e. $80 \%$ of the cases (Table 1) with an average duration of exposure of 30 years and extremes of 2 years and 60 years.

Table 1: Distribution of Patients by Risk Factors.

\begin{tabular}{|c|c|c|}
\hline Risk Factors & Number & Percentage \\
\hline Tobacco & 3 & $15 \%$ \\
\hline Alcohol & 0 & $0 \%$ \\
\hline Exposure to wood smoke & 16 & $80 \%$ \\
\hline Exposure to smoke from gas fire & 0 & $0 \%$ \\
\hline
\end{tabular}

\section{Diagnostic aspects}

The average consultation period was 14.8 months with extremes of 1 to 60 months. The major symptom was dysphonia, present in $100 \%$ of patients at the time of diagnosis. It was associated in $80 \%$ of cases with laryngeal dyspnea, in $30 \%$ of cases with dysphagia, in $40 \%$ with reflex otalgia. Examination of the larynx using indirect laryngoscopy or nasofibroscopy resulted in a budding lesion in 13 patients (65\%) and an ulcerous lesion in 7 patients (35\%). Palpation of the lymph node areas revealed palpable lymphadenopathy in 5 patients, i.e. $25 \%$ of cases. As part of the medical imaging work-up, 10 patients had undergone cervico-thoracic CT scan (Figure 1) and in one of them the CT scan showed pulmonary metastases. The remaining 10 patients had chest X-rays with no objective abnormalities. All the patients in our series had undergone panendoscopy under general anaesthesia and the tumour lesion was localized in $60 \%$ of cases in the glottosus glottic stage, in $20 \%$ of cases in the supraglottic stage, in $15 \%$ in the glottis and glotto-subglottic stage in $5 \%$ of cases. Tumour extension to the digestive tract (pharynx and esophagus) was noted in 3 patients. The histological findings of the biopsy specimen were in favor of squamous cell carcinoma in all patients.

Table 2: TNM Classification of Patients.

\begin{tabular}{|c|c|c|c|c|c|}
\hline & N0 & N1 & N2 & N3 & Total \\
\hline $\mathrm{T} 1$ & $5 \%$ & 0 & 0 & 0 & $5 \%$ \\
\hline $\mathrm{T} 2$ & $0 \%$ & 0 & 0 & 0 & $0 \%$ \\
\hline $\mathrm{T} 3$ & $30 \%$ & $5 \%$ & $5 \%$ & 0 & $40 \%$ \\
\hline $\mathrm{T} 4$ & $40 \%$ & $10 \%$ & $0 \%$ & $5 \%$ & $55 \%$ \\
\hline Total & $75 \%$ & $15 \%$ & $5 \%$ & $5 \%$ & $100 \%$ \\
\hline
\end{tabular}

Citation: Ahmed Houra, Ndour Ngor, Ndiaye Ciré, Pilor Ndongo, Tall Hady, Mbaye Aminata, et al,. Particularities of Larynx Cancer in Women in Senegal. Sch J Oto 4(1)-2020. SJO. MS.ID.000179. DOI: 10.32474/SJO.2020.04.000179.

Figure 1: Cervical CT scan in axial section showing a tumour process of the left vocal cord extended to the anterior commissure.

According to the TNM 2017 classification, 55\% of the cases were classified as T4, $40 \%$ as T3 and $75 \%$ as Table 2 summarizes the TNM classification.

\section{Therapeutic aspects}

A tracheotomy was performed in 19 cases, 14 of which were emergency tracheotomies for severe laryngeal dyspnea. A total laryngectomy associated with bilateral functional cervical curage was performed in 12 patients (Figure 2). Pathological examination of the surgical specimen and its curage product confirmed the diagnosis of squamous cell carcinoma in all cases with invaded margins of resection in 2 cases and a lymph node carcinoma site in 3 cases. Of these patients who underwent surgery, 4 had received additional radiotherapy and 2 had received chemotherapy in the event of tumor recurrence. A carboplatin and taxane-based chemotherapy protocol were instituted in 4 cases including 2 cases of inoperable lesion and 1 case of pulmonary metastasis. One patient classified as $\mathrm{T} 1$ had received exclusive radiotherapy. Three cases in our series presented a refusal to any treatment.

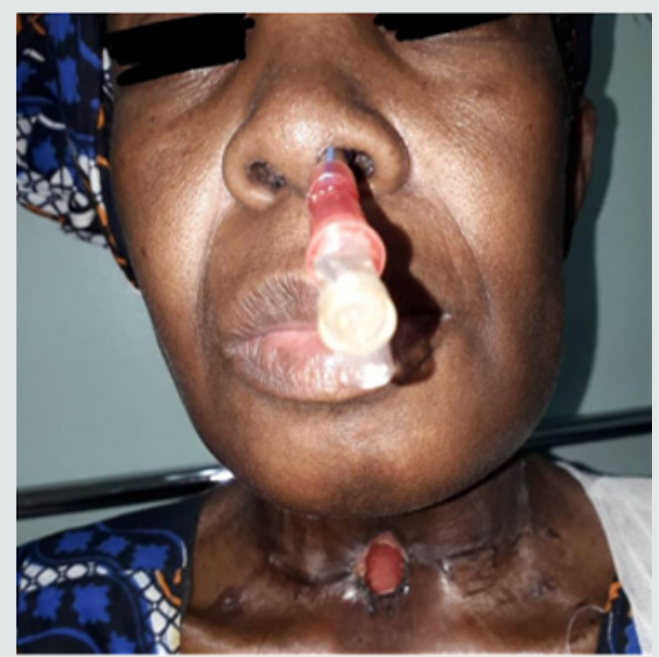

Figure 2: Patient with total laryngectomy and functional cervical lymp nodes excision. 


\section{Evolving aspects}

For an average decline of 30 months with extremes of 6 months and 5 years, we noted complete remission in $50 \%$ of cases. Three cases (15\%) of local and lymph node recurrence with a mean delay of 21 months were noted, two cases of invaded margins and one case of lymph node involvement. Two patients were lost to followup and we deplored 5 cases (25\%) of death in our series.

\section{Discussion}

The Morbi-mortality linked to cancer has been clearly on the rise worldwide for several decades [7]. Laryngeal cancer is the second most common cancer of the head and neck and is a cancer with a high male predominance $(87 \%)[5,6,8,9]$. It ranks $14^{\text {th }}$ in men and $26^{\text {th }}$ in women. As for its incidence, it will probably increase in the coming years, with an estimated 285,720 new cases/year worldwide in 2040 (87\% in men) [6,7]. The median age of women at diagnosis is estimated to be 64 years [10]. Senegal is a country with a low incidence of laryngeal cancer in women compared to countries such as Cuba and Thailand where rates of more than 2 per 100,000 women per year have been reported $[1,11,12]$. Tobacco consumption is the main preventable risk factor for laryngeal cancer [10,13,14]: $44 \%$ of deaths from ADV cancer are thought to be attributable to tobacco use among women [10]. In our series, the low incidence of tobacco intoxication (15\%) and exposure to wood smoke in a large number of our patients (80\%) suggest the predominant role of wood smoke in the genesis of laryngeal cancer in women. In a study conducted by Kouassi et al. [15] in Cameroon on the effects of smoke-related clinical manifestations, all women using wood (100\%) and $98.5 \%$ of those using charcoal showed clinical signs compared to $45.5 \%$ of butane gas users. In sum, smoke from wood and charcoal is more toxic. The need to use this fuel is both a cause and a consequence of poverty, as poor households generally cannot afford cleaner and more efficient fuels and appliances. However, the exact role of this factor is still controversial in the literature, and large-scale studies are needed to accurately understand carcinogenesis in women's laryngeal mucosa.

The average consultation time varies according to the studies; in our patients, it was 14 months as in the Touati et el study [12]. This is a relatively long time compared to the man who consulted on average 3 months after the appearance of the first symptoms $[16,17]$. This delay in consultation could be explained by the fact that dysphonia in women is a trivialized symptom and is considered as vocal abuse. The predominant sub-localization of laryngeal cancer remains a subject of controversy between the different studies. In our series, tumors of the glotto sus glottic stage were the most frequent $60 \%$ compared to that of Touati et al. [12] where glottic localization is the most frequent (54\% of cases). Other teams have stated that the majority of laryngeal cancers in women originate in the supraglottic stage [11,18]. Female laryngeal tumours are diagnosed at an early stage T1-T2 more frequently than in men $[12,19]$. This result is not consistent with our series where $95 \%$ of cases were classified as T3-T4 and only 5\% were classified as T1-T2. Lechuga et al. [20] and Touati et al. [12] found that laryngeal tumours in women were characterised by the absence of adenomegalia at diagnosis. Our series confirms this result since $75 \%$ of the patients were classified as stage N0 lymph nodes. The treatment of laryngeal cancer in women follows the same rules as in men. In our series, 12 patients had undergone total laryngectomy, compared to $47 \%$ in the study by Touati et al. [12], which may be explained by the delay in consultation in our patients. Johansen et al. [21], Harwood et al. [22] and Skladowski et al. [23] found a better prognosis in female patients. On the other hand, in a large number of published works, sex does not seem to be a prognostic factor for survival $[24,25]$. This controversy is difficult to resolve because of the low representation of women in the published series, which makes it difficult to demonstrate a statistically significant difference. After an average follow-up of 30 months, $50 \%$ of these patients were in sustained complete remission and none of them benefited from vocal rehabilitation. A review of the literature shows that the prognosis is superimposable on that of male patients and that wood smoke appears to be the most convincing risk factor.

\section{Conclusion}

Laryngeal cancer in women is a particular area that is still insufficiently explored. A better knowledge of the risk factors would certainly contribute to improving the prognosis.

\section{References}

1. Diallo BK, Loum B, Tall A (2004) Preliminary study of laryngeal cancer in Senegalese women. Bull Med Owendo 24: 5-7.

2. Brunin F, Rodriguez J, Cougniot-Lescure S (1995) Particularities of laryngeal cancers. Rev Praticien (Paris) 45: 848-854.

3. Hill C (2000) Epidemiology of cancers of the upper aerodigestive tract. Bull Cancer Suppl CME 5: 5-8.

4. Peng J, Raverdy N, Ganry O (2000) Descriptive epidemiology of upper aerodigestive tract cancers in the Somme department. Bull Cancer 87(2): 201-206.

5. Zitouni S, Saidia A, Djerad NA (2014) Laryngeal cancer in women. Oral communications Annales françaises d'otorhino-laryngologie et de pathologie cervico-faciale 131 (2014): A75-A103

6. Globocan (2018) Cancer tomorrow. A tool that predicts the future cancer incidence and mortality burden worldwide from the current estimates in 2018 up until 2040.

7. Guerlain J, Janot F (2019) Epidemiology, risk factor, prevention of laryngeal cancer. Barry B, Malard O, Morinière S (Eds.), Cancer of the larynx. Report 2019 of the Sociéte francaise d'oto-rhino-laryngologie et de chirurgie de la face et du cou, Masson, Paris 2019: 24-28.

8. Haque MR, Abdullah M, Alauddin M (2002) Carcinoma of the larynx: topographical distribution. Mymensingh Med J 11(1): 15-21.

9. Pasquesoone X, Chevalier D (2000) Cancers of the hypopharynx and larynx: epidemiology, diagnosis and long-term complications of treatment. Rev practitioner (Paris) 50(1): 19-23.

10. (2018) National cancer Institute. Cancers in France. Edition 2017. Boulogne-Billancourt, INCa, Paris, France.

11. Sas Korczynska B, Korzeniowski S, Skolyszewski J (2003) Cancer of the larynx in females. Cancer Radiotherapy 7: 380-5.

12. Touati S, Ghorbal H, Ben Younes A, Attia Z, Gritli S (2014) Squamous cell carcinoma of the larynx in females. J Tun ENT 31: 13-16.

13. Cogliano VJ, Baan R, Straif K (2011) Preventable exposures associated with human cancers. J Natl Cancer Inst 103(24): 1827-1839. 
14. Gallus S, Bosetti C, Franceschi S (2003) Laryngeal cancer in women: tobacco, alcohol, nutritional, and hormonal factors. Cancer Epidemiol Biomarkers Prev 12(6): 514-517.

15. Kouassi B, Horo K, Ahui B (2012) Clinical manifestations of kitchen smoke among women in African settings. Rev Malad Resp 29: 398-403.

16. (2015) French Society of ENT and Surgery of face and neck . Recommendation for clinical practice. Organization of the initial care pathway in upper ADT cancerology, SFORL, Paris, France.

17. Righini CA, Colombe (2019) Initial assessment - TNM classification. Barry B, Malard O, Morinière S (Eds.), Laryngeal cancer. 2019 Report of French Society of ENT and Surgery of face and neck Masson, Paris, France, p. 48-52.

18. Sahraoui S, Acharki A, Benider A (1998) Cancer of the larynx in women. Cancer Radiotherapy 2: 604-605.

19. Shvero J, Hader T, Feinmesser R (1996) Laryngeal carcinoma in females European Journal of Surgical Oncology 22: 61-64.
20. Lechuga R, Martín C, Mínguez I (2000) Study and incidence of carcinoma of the larynx in women. Acta Otorrinolaringol Esp 51(2): 129-132.

21. Johansen LV, Overgaard J, Hjelm Hansen M (1990) Primary radiotherapy of T1 squamous cell carcinoma of the larynx: analysis of 478 patients treated from 1963 to 1985. Int J Radiat Oncol Biol Phys 18(6): 13071313.

22. Harwood AR, Deboer G, Kazim F (1981) Prognostic factors in T3 glottic cancer. Cancer 47(2): 367-372.

23. Skladowski K, Zajusz A, Swiatnicka J (1996) Prognostic factors in radiotherapy of supraglottic cancer. Otolaryngol Pol 50(6): 679-686.

24. Walasek T, Dymek P, Kowalska T (1997) Is gender a prognostic factor in early stage laryngeal cancer treated with radiotherapy? Otolaryngol Pol 51: 139-142.

25. Ramroth H, Schoeps A, Rudolph E (2011) Factors predicting survival after diagnosis of laryngeal cancer. Oral Oncology 47 (12: 1154-1158.

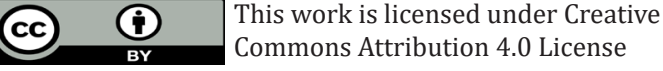

To Submit Your Article Click Here:

Submit Article
DOI: $10.32474 /$ SJ0.2020.04.000179

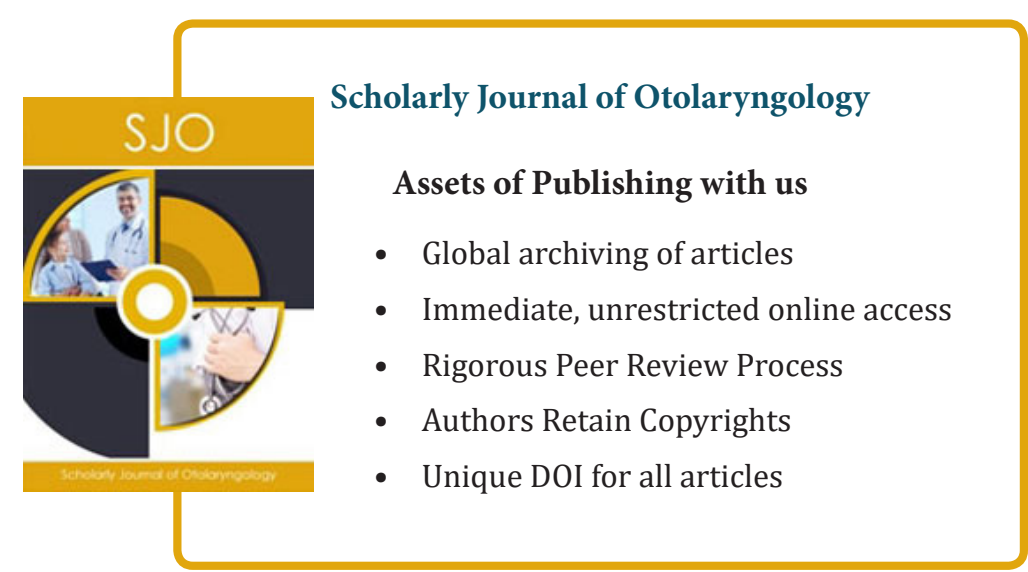

